\title{
The Impact of the Use of Information Technology in Improving the Quality of Services: A Field Study of Fast-Food Restaurants in Jordan
}

\author{
Ahmad Fawwaz Malkawi \\ Department of Administrative Sciences, Jerash University, Jordan
}

doi: 10.19044/esj.2017.v13n23p359 URL:http://dx.doi.org/10.19044/esj.2017.v13n23p359

\begin{abstract}
The study aimed to determine the impact of information technology in improving the quality of the service of fast-food restaurants in Jordan. In achieving the objectives and testing of the hypotheses of this study, a questionnaire was developed especially for the collection of data from a study sample. The number of questionnaires analyzed was 66. By using appropriate statistical tests, the results of the study showed that fast-food restaurants uses information technology to improve the quality of their service. There is a strong relationship between information technology and improving the quality of the service. Also, information technology directly and positively affects the process of improving the quality of service in fastfood restaurants. The study recommended the need to employ information technology more in improving the quality of the service in fast-food restaurants. It also works to achieve greater interaction between information technology and the beneficiaries of the services provided by these restaurants. In addition, there is the need for better use of information technology to form a link between the administration and clients.
\end{abstract}

Keywords: Information technology, quality of service, fast-food restaurants, Jordan

\section{Introduction}

The rapid technological developments of the world were represented clearly in the performance of different economic sectors, in particular the service sector. In the service sector, the organizations working in this field tend to create a special competitive advantage by helping it to survive and compete in the business environment. This, however, established a desire for the service organizations to possess a greater capacity than technology to drive it through innovation, excellence, and possession of advanced 
information systems which has helped in raising the quality of services provided to its customers.

Consequently, fast-food restaurants are one of the institutions concerned in keeping pace with the developments and systems in information technology. This is as a result of the fast changes and intense competition witnessed by the institutions working in this field. It is also attributed to the services' dependence on the services provided based on quality in the first place and reputation in the second place.

\section{Study Importance}

The importance of the study stems from the growing and rapid role played by Information Technology (IT) in improving the quality of services provided in fast-food restaurants. However, this plays an important role in activating the national economy and also contributes noticeably in reducing unemployment and employing a large number of employees of both sexes.

\section{Study Problem}

The study problem was represented using the following question: What is the impact of information technology in improving the quality of services provided in fast-food restaurants? Here are its sub-questions:

-What is the impact of information technology in improving the concrete elements in fast-food restaurants?

-What is the impact of information technology in improving the dependence of fast-food restaurants?

-What is the impact of information technology in improving response in fastfood restaurants?

-What is the extent of the impact of information technology in improving insurance at fast-food restaurants?

-What is the impact of information technology in increasing sympathy with customers in fast-food restaurants?

\section{Study Objectives}

The study was conducted from an overall objective of determining the impact of information technology in improving the quality of services provided in fast-food restaurants operating in Jordan.

It also provides the answers to the questions contained in the research problem. 


\section{Study Sample}

Independent variable

Information technology improving the quality of service

\begin{tabular}{|l|l|}
\hline - Software resources. & \\
-Equipment resources. & - Tangibility \\
-Networking & - Dependence \\
resources. & - Respond \\
-HR. & - Security \\
& \\
\hline
\end{tabular}

\section{Study Hypotheses}

The study lies on the following key hypothesis: There is a positive statistically significant impact of the information technology in improving the quality of service provided in fast-food restaurants operating in Jordan. Thus, here is its sub - hypotheses:

-The First Sub-hypothesis: There is a statistically significant impact of information technology in improving the concrete elements in fast-food restaurants operating in Jordan.

-The Second Sub-hypothesis: There is a statistically significant impact of information technology in improving the dependence of fast-food restaurants operating in Jordan.

-The Third Sub - hypothesis: There is a statistically significant impact of information technology in improving the response in fast-food restaurants operating in Jordan.

-The Fourth Sub-hypothesis: There is a statistically significant impact of information technology in improving insurance at fast-food restaurants operating in Jordan.

-The Fifth Sub - hypothesis: There is a statistically significant impact of information technology in increasing sympathy with customers in fast food restaurants operating in Jordan.

\section{The Theoretical Framework of the Study Information Technology}

According to Daft (2001), technology can be defined as the methods, machinery, and activities used to transform the organizational inputs such as materials, information, and ideas into outputs like commodities and 
services. Laudon and Laudon (2003) defined it as data that has been formulated into a meaningful and useful way for individuals. Also, Al Jassem (2005) defines it as a set of interconnected terms that include fast methods of processing information through using the computer, applying the statistical and mathematical methods in solving problems, and imitating thinking through the computer software. However, according to Kroeneke (2011), Information Technology (IT) are the products, methods, inventions, and criteria used for the purpose of producing information and it includes physical equipment, software, and data.

\section{The importance of Information Technology}

The importance of information technology is evident through what the support offers to individuals, organizations, and community. Information Technology (IT) helps everyone to have access to the means, instruments, and technologies in achieving their objectives. Therefore, the importance of information technology is evident through its applications that contribute to strengthening the elements of the competitive advantage of organizations. This is evident as businesses expand, costs are reduced, more savings on time, effort and high flexibility are done to modernize and develop the performance, new resources and returns are achieved to the organization, response speed to customers is improved, and there is a technical base of the construction of knowledge management in the organization (Al - Lami, 2009). The importance of information technology can be more clearly shown by identifying the reasons that led to its wide spread in the productivity and service organizations. However, these reasons are (Al - Jasem, 2005):

1. Increasing productivity

2. Improving services

3. Controlling complexity

4. Flexibility

\section{Information Technology Components}

Information Technology consists of five main components (Ajam, 2007; Laudon \& Laudon, 2010). They are:

1. Hardware: The term refers to the physical components on which the information technology system depends. It includes the input methods, the CPU, the output means, various means of storage, and means of communications.

2. Software: This is the written instructions in a language understood by the computer. It includes two types of programs: programs for operating the hard entity and the software applications which the final user deals with. 
3. Communication Networks: This is the means by which data, information, knowledge, and software are exchanged among people through certain means of information technology and within different networks. Each of these networks work on a limited scale and the other covers a wide geographical area. Data and information exchange can be limited to a certain scale between people and organizations or can be made accessible to everyone.

4. Database: This is a repository for the data, themes, and organized and interconnected files with each other. It describes the current and previous operations of the organization, which can be referred to quickly by computers associated with various programs. Database can be added, modified, and modernized to keep pace with constantly evolving variables. It enables managers to make strategic decisions in accordance with the right basis, and it also enables users to do their jobs more efficiently.

5. People: People are the most important structural element in the information technology system. It can be divided into two categories. The first, which is the dominant are called the end users, who deals with the application programs such as beneficiaries of it and its applications without giving precise details of the programming operations. The second class is the specialists in the field of computer who design computers and installs different programs on them, whether they are application software or system software.

\section{Service Quality}

Most companies have realized that the customer's respect and satisfaction should be achieved due to the importance of possessing a competitive and commercial attribute. However, this can be achieved by presenting the product that satisfies the customer's needs and desires. In achieving this, companies in general and service companies in particular should prepare an integrated team to provide the service to customers. Also, they should continuously train them to ensure the continuity of their ability to satisfy customers since the quality of service is mainly dependent on the cooperation between the service provider and the recipient.

This, therefore, shows that employees are acquired with attributes to perform their role positively to have a guaranty of employment especially in developed restaurant companies and hotels of classified degrees. These restaurants and hotels requires the highest degree of the employees' satisfaction through the employees' master of the art of negotiation, dialogue, the method of presenting the service through welcoming and dialoguing with the client so as to choose the service, and how to prepare the items needed by the customer (Al-Omari, 2007). In other words, these 
companies must offer a high quality services (especially restaurants) to meet the needs and desires of customers.

Quality means the ability to meet the needs and desires of customers through making a commodity or providing a service that meets the needs and requirements of employees (Al-Sairafi, 2003). The service means the ability to satisfy the customer needs and exceeds his/her expectation (Jiang, 2002). However, Kotler and Asmstrong (2007) define it as an activity or benefit that can be provided by one party to another and it might not be concrete with no obligation. Additionally, the provision of the services is often associated with another product.

The quality of service has been defined as a set of features and characteristics of the service that contribute in meeting the desires of consumers. These includes: price, safety, availability, dependence, and usability (Al-Sairafi, 2003). However, Beer (2003) defines it as the total qualities and characteristics enjoyed by the service. This is such that it is able to satisfy the customer's needs and satisfaction.

\section{The Dimensions of the Service Quality}

Zeithaml and Valeria (2006) developed five key dimensions of the service quality which were called ServQual model. These dimensions are used to measure the quality of the service and they are:

1. Tangibility: It includes all the physical things related to the service such as the facilities, production equipment, appreciation for the service, as well as the external appearance of the service providers.

2. Dependence: This is the service performance and achievement for the purpose it is produced for.

3. Response: It reflects the readiness of workers for the positive interaction with customers and the speed in meeting their demands.

4. Insurance: The feeling of security in dealing with the organization and trusting its offers.

5. Sympathy: It represents the extent of understanding the needs, interests, and circumstances of the customer.

Consequently, as for the field of information Technology and information systems of service outputs, the quality of information systems for the final user is providing the service. One of his quality indicators involves the achievement of the desires of the final user and his ambitions totally. One of the most common instruments is the service quality scale "ServQual" which focuses on quality and how to reach it through limiting the difference between the user's use of service and his expectations from service (Al-Oroud \& Shukur, 2009). Thus, this scale is considered one of the most prominent models which show the service quality measurement. 


\section{Main Characteristics of Customer Service}

Service production process is affected by the extent of interaction between the provider and the beneficiary. Therefore, this calls for the development of the service providers' skills continuously, controlling their performance, and educating the public about the services and methods of getting them. Services, most especially, have characteristics different from the physical product. Some of these characteristics are (Al-Dmour, 2005):

\section{- Intangible \\ - $\quad$ The service cannot be separated from its provider \\ - $\quad$ The service is not capable of being stored \\ - Its ownership cannot be transferred \\ - $\quad$ Non-measurable}

Furthermore, the characteristics of this service are applicable to restaurants where these services are intangible products. Also, they are introduced to satisfy the needs and desires of restaurants' clients in order to achieve a great deal of comfort and reassurance. Services at restaurants can be distinguished through continuity in providing such services. Therefore, this requires an ongoing connection, interaction, and relationship with customers. For restaurants to maintain their customers, they must provide their services to the highest possible quality by taking into account the fact that the customer is attended to as soon as possible in a friendly manner. What increases the importance of customers' service in the tourism sector, especially in hotels and restaurants service, is its direct link to the exploitation of the tourism sites by meeting the needs of tourists so as to ensure a positive real return.

\section{The Principles of Quality Improvement}

The principles of improving quality depends on the nature of the senior management and its adoption of quality, the precise identification of objectives, and enabling and encouraging employees to work as a team (Al - Azzawi, 2002).

\section{Methods of Improving Quality}

The organization's desire to increase its market share, especially in light of the intense competition it faces, made it find a set of key means in improving quality (Hmoud, 2006; Mualla \& Tawfic, 2002). These means are:

1. Training employees

2. Management supreme court

3. Competitors 
4. Focusing on clients

5. Participation

\section{Steps to Achieve Service Quality}

The most important steps in achieving the quality of service include (Hamoud, 2006):

- $\quad$ Attracting the attention of customers.

- $\quad$ Identifying the desires and needs of customers.

- $\quad$ Convincing customers with the service and handling objections.

- Emphasizing on customers' continuous interaction with the organization.

\section{International Market of Fast-food Restaurants}

The wide spread of fast-food restaurants comes as a result of the globalization and deepening of its concepts which are based on the free transmit of capital, information, technology, and human resources without constraints and obstacles limiting this freedom. Due to the great progress in information and communication technology, information can be easier, faster, and more effective. Goods and services come as a result of freeing the international market which allows several companies specialized in making fast food to go out of the local frame to work in the international environment. Hence, this requires a continuous analysis and a precise dealing with the international environment which contributed to showing many concepts. Some of them are the concept of the international customer as a new marketing opportunity. Here, the overall trend in developing the market tends towards more interaction with the customer and the products he asks for far from typicality (Abu Qahaf, 2002). Therefore, the success of the fastfood companies at work outside its local environment depends on their ability to adopt environmental factors that affect their survival and continuity as a system. In addition, the marketing environmental powers do not affect the decisions of entering the external markets, but it affects the decisions on how to provide a service for such markets by the workers of these companies (Abu Rumman, 2000).

\section{Previous Studies}

The researchers mentioned some studies that are believed to be relevant to the subject of the study. They serve the purpose for which this study was conducted:

\section{The Arabic Studies}

- Al - Khatib and al - Husseini (2002) aimed to test the nature of the relationship between the e-commerce and the strategic center for the 
Jordanian industrial companies. The study reached a number of the most important results such as the presence of a clear relationship between e commerce and the strategic center of the sample companies. The research also presented a set of recommendations. The most important of them is that companies should depend on e-marketing and e-commerce through analyzing their strategic analysis and strategic center to identify the strengths and weaknesses of the environmental threats and the imbalances and shortcomings in methods and system.

- Yassin and al-Tai (2004) aimed to evaluate the theoretical framework for the standards of websites' development in general, evaluate the websites of the sample hotels, and make a comparison among hotels. This comparison is done on the basis of the assessment of hotel standards through the distribution of a questionnaire to the customers of the sample hotels in coordination with the booking officer who booked and payed online. The study concluded that the criteria of the website, service quality, information content, and the interface of the beneficiary affect the evaluation of the sample hotels websites on the World Wide Web. One of the main recommendations of this study is the interest of the hotel departments in designing websites on the internet and choosing the efficient cadre to manage these websites.

- The study of Al-Sheshani (2009) sought to identify the impact of using e-commerce on the hotel services market in Jordan. It concluded that there is a positive and statistical significance between the use of e-commerce and the development of the service. The study recommended the adoption of the concept of e-commerce in the service sector due to its importance and positive impact on the performance of those organizations.

- Heda and Abd Al-Haq (2010) aimed to identify the role that the technology plays in improving the competitiveness of the tourism companies. This is reflected clearly in most modern tourism activities and services both in terms of management, organization, contact, or other ways of dealing.

\section{Foreign Studies}

- Venkatesh Shankar, Amy K. Smith and Arvind (2002) aimed to identify the impact of the means of communication through the internet based on the customer satisfaction and the degree of loyalty. It also identifies the relationship between the customer satisfaction and loyalty, where the researchers prepared a synchronous model to gather information which consists of two parties who are the customers getting the service through traditional methods and customers who receive service through the website of the hotel industry. The most important findings of the study show that the customer satisfaction through the Internet and traditional methods is 
almost at the same level. However, as for the loyalty of the service provider, it is higher when it is via the Internet. The study also showed that there is a correlation between the customer satisfaction and loyalty such that the presence of one reinforces the other. In addition, this relationship is strengthened by dealing through the Internet in the long term.

- Bruce Adams (2004) focused on the role of the Internet in increasing service sales; it concluded that there is a rapid increase in the number of bookings through the Internet for hotels. He further opines that expectations in the future indicate that the Internet will contribute by $27 \%$ of the total sales realized from hotels rooms through the hotel website. However, such percentage is increasing, and it showed that the Internet does not only affect the sales realized from hotel rooms, but also its marketing and distribution through the Internet.

- Harmsworth, GR (2006) aimed to find out how to take advantage of the geographic information systems in marketing the tourist sites in New Zealand. The study, therefore, showed the importance of GIS in tourism marketing and the possibility of using these systems to perform various analyzes.

\section{The Practical Side: The Procedures and Results of the Field Study Sources of Data Collection: Data were collected from two sources:} Arab and foreign books and periodicals on the subject.

- $\quad$ Primary Sources: They are represented in getting access to the data through a questionnaire designed for the purpose of study. They were distributed to the sample restaurants to cover the practical aspect of the study.

\section{Study Society and Sample}

The study population consisted of all the managers of the branches of the fast food restaurants in Jordan. Hence, the study sample consisted of (66) managers of the branches of fast food restaurants.

\section{Tests on the Questionnaire}

\section{(A) Instrument Validity}

- Face Validity: A process of confirming that the items contained in the questionnaire leads to an accurate data collection. To achieve this, the questionnaire was presented to a group of specialist teachers and then to some of the members of the study sample. This was to ensure they understand the phrases and words used and the degree of clarity and ease for the study sample. 
- $\quad$ Content Validity: It is intended to express the extent of the items of the questionnaire for the dimensions of the study. Also, each dimension is exactly represented with a group of questions. However, this was confirmed by being presented to professional and academic specialists.

(B) Instrument Reliability

Cronbach's Alpha for the dimensions of the independent variable of information technology was calculated by 0.76 . This calculation was for the dimensions of the dependent variable in improving the service quality $(0.86)$. On the other hand, its value for the study tool as a whole was 0.903 , which is higher than the minimum (0.50-0.60) in the exploratory studies. Therefore, it would be acceptable for the purposes of statistical analysis. The adopted tests provide indications for the face validity, content validity, and the reliability of the study instrument.

Analyzing, Testing, and Discussing the Variables of the Field Study

Through the analysis of personal and functional characteristics, Table 1 shows the distribution of the sample according to experience, academic qualification, and monthly income, which is as follows:

Table 1 . The distribution of the sample depending on the personal variables

\begin{tabular}{|l|c|c|c|}
\hline Variable & Level & Frequency & Percentage \\
\hline \multirow{4}{*}{ Experience } & Less than 5 years & 40 & 60.6 \\
\cline { 2 - 4 } & 5-10 years & 23 & 34.8 \\
\cline { 2 - 4 } & $10-15$ years & 3 & 4.5 \\
\cline { 2 - 4 } & More than 15 years & - & - \\
\hline \multirow{3}{*}{ Qualification } & Diploma or less & 27 & 40.9 \\
\cline { 2 - 4 } & BA & 38 & 57.6 \\
\cline { 2 - 4 } & Postgraduate & 1 & 1.5 \\
\hline \multirow{3}{*}{ Monthly Income } & Less than 200 dinars & 8 & 12.1 \\
\cline { 2 - 4 } & 200-350 dinars & 36 & 54.5 \\
\cline { 2 - 4 } & More than 350 dinars & 22 & 33.3 \\
\hline & Total & 66 & 100.0 \\
\hline
\end{tabular}




\section{Arithmetic means and standard deviations of the study variables First: The Independent Variable (Information Technology Systems)}

Table 2. The arithmetic means and standard deviations of the answers of the study sample on the items of the independent variable: information technology systems

\begin{tabular}{|c|c|c|c|}
\hline $\mathrm{N}$ & Item & Means & $\begin{array}{l}\text { Standard } \\
\text { Deviation }\end{array}$ \\
\hline 1 & $\begin{array}{l}\text { The computer software used in the restaurant meets the demands and needs of } \\
\text { customers. }\end{array}$ & 4.42 & 0.61 \\
\hline 2 & $\begin{array}{l}\text { In case of certain damage, the computer software provides the guidance and } \\
\text { information to deal with it. }\end{array}$ & 4.09 & 0.80 \\
\hline 3 & The software is constantly updated. & 4.18 & 0.78 \\
\hline 4 & $\begin{array}{l}\text { The restaurant management is concerned with the quality of the software used in } \\
\text { their operations. }\end{array}$ & 4.44 & 0.70 \\
\hline \multicolumn{2}{|c|}{\begin{tabular}{|l|l} 
Software Resources \\
\end{tabular}} & 4.28 & 0.48 \\
\hline 5 & $\begin{array}{l}\text { The equipment of the software available in the restaurant facilitates the } \\
\text { comparison between the previous works and predicting the future ones. }\end{array}$ & 4.42 & 0.66 \\
\hline 6 & $\begin{array}{l}\text { The restaurant management trusts the quality of the technological equipment and } \\
\text { its mechanism. }\end{array}$ & 4.32 & 0.75 \\
\hline 7 & $\begin{array}{l}\text { The restaurant has special and advanced technological equipment to meet the } \\
\text { needs of customers. }\end{array}$ & 4.41 & 0.76 \\
\hline \multicolumn{2}{|c|}{ Equipment Resources } & 4.38 & 0.53 \\
\hline 8 & The restaurant offers the direct reservation service through the internet. & 3.05 & 1.36 \\
\hline 9 & The restaurant offers the demand service through the internet. & 2.97 & 1.36 \\
\hline 10 & $\begin{array}{l}\text { The restaurant has a website for the customer service to identify their complaints } \\
\text { and suggestions. }\end{array}$ & 4.18 & 1.16 \\
\hline 11 & $\begin{array}{l}\text { The restaurant communicates with customers by the electronic networking (such } \\
\text { as Facebook). }\end{array}$ & 3.79 & 1.27 \\
\hline 12 & $\begin{array}{l}\text { There is a network linking the restaurant branches with all the governorates of } \\
\text { the Kingdom (internet). }\end{array}$ & 4.27 & 1.02 \\
\hline \multicolumn{2}{|c|}{ Network Resources } & 3.65 & 0.84 \\
\hline 13 & $\begin{array}{l}\text { The management takes interest in developing the human resources in the } \\
\text { restaurant. }\end{array}$ & 4.64 & 0.60 \\
\hline 14 & The management uses employees specialized in the field of customer service. & 4.06 & 1.14 \\
\hline 15 & The company provides physical and moral incentives for employees. & 4.09 & 1.08 \\
\hline \multicolumn{2}{|c|}{ HR } & 4.26 & 0.69 \\
\hline \multicolumn{2}{|c|}{ Independent variable: Information Technology } & 4.14 & 0.63 \\
\hline
\end{tabular}

Table 2 shows the arithmetic means of the items forming the dimensions of the independent variable. Thus, the arithmetic means of such dimensions were as follows: hardware resources (4.38), software resources (4.28), human resources as a whole (4.26), and networks resources as a whole (3.65). However, the arithmetic mean of the independent variable as a whole was 4.14, which indicates the availability of the resources of IT in fast food restaurants by a high degree. 


\section{Second: The Dependent Variable (Services Improvement)}

Table 3. The arithmetic means and standard deviations for the answers of the study sample on the items of the dependent variable of the services improvement

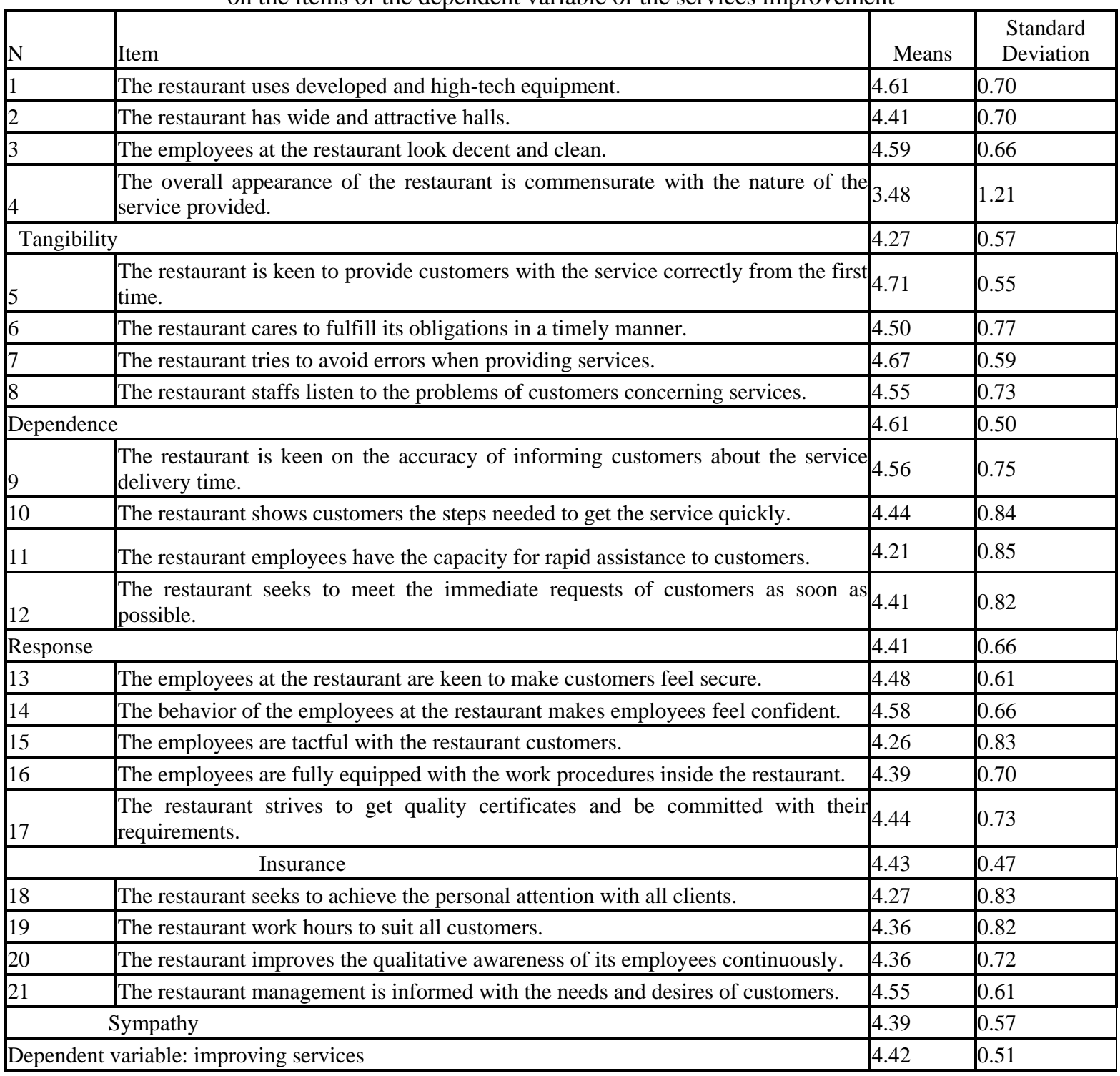

Table 3 shows the arithmetic means of the items representing the dimensions of the dependent variable. Thus, the arithmetic means of the dimensions were: dependence (4.61), insurance (4.43), response (4.41), sympathy (4.39), and tangibility (4.27). However, the arithmetic mean of the dependent variable as a whole was 4.42 , which indicates that the fast-food restaurants have a high focus on quality and in improving it. This is to ensure 
customer satisfaction by providing services that satisfy and meet their needs and desires.

\section{Testing Hypotheses}

To test the relationship between the variables of the study, Pearson correlation coefficient was used as shown in Table 5. In Table 5, the table data indicate that all correlations were statistically significant between the study variables by varying degrees. They also indicate a strong positive correlation at the significance level $(\mathrm{A} \leq 0.05)$ between the independent variable of information technology with its different dimensions and the dependent variable of services quality improvement with its different dimensions. Therefore, the value of the correlation was 0:59, which suggests that the greater the degree of efficiency of information technology, the more the improvement of the services provided to customers by the fast-food restaurants.

Table 4. The matrix of Spearman correlation coefficients between the axes of the technology and information systems and the axes of the field of improving services

\begin{tabular}{|l|l|l|l|l|l|l|l|}
\hline \multirow{2}{*}{\begin{tabular}{l} 
IT Dimensions \\
\cline { 3 - 8 }
\end{tabular}} & \multicolumn{2}{|l|}{ Dimensions of Quality Improvement } & $\begin{array}{l}\text { Quality } \\
\text { Improveme } \\
\text { nt }\end{array}$ \\
\cline { 2 - 9 } $\begin{array}{l}\text { Information } \\
\text { Technology }\end{array}$ & $\begin{array}{l}\text { Tangibility } \\
\text { Correlation }\end{array}$ & Dependence & Response & Insurance & Sympathy \\
\cline { 2 - 9 } & $\begin{array}{l}\text { Statistical } \\
\text { Significance }\end{array}$ & 0.62 & 0.27 & 0.44 & 0.37 & 0.40 & 0.59 \\
\hline
\end{tabular}

Source: prepared by the researcher based on the SPSS results

Impact of Information Technology in Improving the Quality of Service

Since it has been proven that there is a statistically significant correlation between the independent variable and the dependent variable, it is possible to discuss and identify the role of information technology in improving service quality. Accordingly, the effect hypothesis was tested using the Path Analysis. The following are the results of the regression analysis based on the impact of the dependent variable of the information technology based on the process of improving the quality of different dimensions:

Table 5. The results of the simple regression equation to study the impact of the information systems technology on the axes of the services improvement

\begin{tabular}{|l|c|c|c|c|c|c|}
\hline Axis & $\beta$ & $\mathrm{T}$ & $\mathrm{R}$ & $\mathrm{R}^{2}$ & $\mathrm{~F}$ & $\begin{array}{c}\text { Statistical } \\
\text { Significance }\end{array}$ \\
\hline Tangibility & 0.62 & 6.32 & 0.62 & 0.38 & 40.01 & 0.00 \\
\hline Dependence & 0.27 & 2.27 & 0.27 & 0.07 & 5.19 & 0.02 \\
\hline Response & 0.44 & 3.87 & 0.44 & 0.19 & $15: 03$ & 0.00 \\
\hline Insurance & 0.37 & 3.13 & 0.37 & 0.13 & 9.82 & 0.00 \\
\hline Sympathy & 0.40 & 3.50 & 0.40 & 0.16 & $12: 29$ & 0.00 \\
\hline Improving the quality of service & 0.59 & 5.90 & 0.59 & 0.35 & 34.88 & 0.00 \\
\hline
\end{tabular}

Source: prepared by the researcher based on the SPSS results 
Table 5 shows the following:

1. There is a statistically significant impact at the significance level $(\mathrm{A}=0.05)$ for information technology in terms of tangibility. Here, the values of $B, T, R, R^{2}$, and $F$ were $0.62,6.32,0.62,0.38$, and 40.01 respectively, which are statistically significant values. Accordingly, the first sub-hypothesis is approved.

2. There is a statistically significant impact at the significance level $(\mathrm{A}=0.05)$ for information technology in terms of dependence. Here, the values of $\mathrm{B}, \mathrm{T}, \mathrm{R}, \mathrm{R}^{2}$, and $\mathrm{F}$ were $0.27,2.27,0.27,0.07$, and 5.19 respectively, which are statistically significant values. Accordingly, the second sub-hypothesis is approved.

3. There is a statistically significant impact at the significance level $(A=0.05)$ for information technology in terms of response. Here, the values of $\mathrm{B}, \mathrm{T}, \mathrm{R}, \mathrm{R}^{2}$, and $\mathrm{F}$ were $0.44,3.87,0.44,0.19$, and 15.03 respectively, which are statistically significant values. Accordingly, the third subhypothesis is approved.

4. There is a statistically significant impact at the significance level $(A=0.05)$ for information technology in terms of insurance. Here, the values of $\mathrm{B}, \mathrm{T}, \mathrm{R}, \mathrm{R}^{2}$, and $\mathrm{F}$ were $0.37,3.13,0.37,0.13$, and 9.82 respectively, which are statistically significant values. Accordingly, the fourth subhypothesis is approved.

5. There is a statistically significant impact at the significance level $(A=0.05$ for information technology in terms of Sympathy. Here, the values of $\mathrm{B}, \mathrm{T}, \mathrm{R}, \mathrm{R}^{2}$, and $\mathrm{F}$ were $0.40,3.50,0.40,0.16$, and 12.29 respectively, which are statistically significant values. Accordingly, the fifth subhypothesis is approved.

6. There is a statistically significant impact at the significance level $(A=0.05)$ for information technology in terms of improving the services quality as a whole. Here, the values of $\mathrm{B}, \mathrm{T}, \mathrm{R}, \mathrm{R}^{2}$, and $\mathrm{F}$ were $0.59,5.90$, $0.59,0.35$, and 34.88 respectively, which are statistically significant values. Accordingly, the main hypothesis is approved.

\section{Conclusion}

1. The study showed that fast food restaurants use information technology, and it showed the great importance of using it in the service sector.

2. The study confirmed that fast food restaurants adopt improving service quality in their work by a high degree. This is a very important instrument to face the big competition in its field.

3. The study showed that there is a strong relationship between information technology and improving the quality of service. The 
more information technology that is sufficiently used, the more the improvement of service quality.

4. The study revealed that the impact of information technology positively and directly influences the process of improving the quality of service at fast-food restaurants.

\section{Recommendations}

In light of the results that have been reached, the researcher gave the following recommendations:

1. Increasing the focus on the employment of information technology more effectively in the process of improving the service quality in fast food restaurants.

2. Working on achieving a greater interaction between information technology and the beneficiaries of the services offered by these restaurants through the adoption of easy and safe applications that encourage customers to use them. This should be done gradually.

3. Using information technology for a better correlation between management and customers. The administration should work on a rapid response of the complaints of workers and achieve their requirements which make them feel secured. This encourages them to communicate continuously thereby providing the restaurant with observations continuously.

\section{References:}

1. Abu Qahaf \& Abd Al-Salam (2002). International Marketing, University House of publishing, Alexandria.

2. Abu Rumman \& Asaa'd Hamid (2000). Tourism and hospitality marketing and the scientific bases, Al-Hamed House of Publishing, Amman, Jordan.

3. Al - Jassem Jafar (2005). Information technology, Osama house for Publishing and Distribution, Amman, Jordan.

4. Al-Azzawi Mohammed Abd Al-Wahab (2002). Quality and environment systems ISO9000 and ISO14000, Wael house of publication, Amman, Jordan.

5. Al-Dmour Hani Hamid (2005). Marketing services, Wael house for publication, Amman, Jordan.

6. Al-Lami Ghassan (2010). Information technology in business organizations: uses and applications, Al-Warraq house of Publishing and Distribution, Amman, Jordan.

7. Al-Sairafi Mohammad Abd Al-Fattah (2003). Pioneer administration, Al-Safa house for Publishing and Distribution, Amman, Jordan. 
8. Hammoud Khudair Kadim (2006). A training course in Total Quality Management, Center of the Studies, Consultations and community service at the Hashemite University, Amman, Jordan.

9. Mualla Naji and Tawfiq Raef (2002). Marketing assets, Wael house for publication, Amman, Jordan.

10. Ajam, Ibrahim Mohammed Hassan (2007). Information technology and knowledge management and their impact on the strategic option: a comparative analysis of the views of a sample of the Iraqi civil and public bank managers (unpublished doctoral Dissertation), AlMustansiriya University, Iraq.

11. Al-Khatib Fahd \& Al-Husseini Falah (2002). e-commerce and its impact on the strategic center of companies, an applied study on a sample of Jordanian industrial companies, Journal of Administrative Sciences' Studies, Vol. 29, Issue 1.

12. Al-Omari Malik \& Adnan Ali (2007). The impact of improving the service quality on the customers' satisfaction in the Jordanian restaurants sector from the perspective of managers, field Study (Master Thesis), the Hashemite University, Jordan.

13. Al-oroud Shaher Falah \& Shuker Talal Hamadoun (2009). The quality of information technology and its impact on the efficiency of internal audit in the Jordanian industrial and service public shareholding companies, Jordan Journal of Business Administration, University of Jordan, Jordan.

14. Al-Sheshani, Sami Hamid Abd Al-Hamid (2009). The impact of using e - commerce on the hotel services market: a field study on the first - class hotels in Jordan (Master Thesis), Al - Bayt University, Mafraq, Jordan.

15. Rice, Heda, Abd Al-Haq, \& Ben Al-Turki, Zainab (2010). e-tourism and its role in activating the tourism sector, the International Forum of the economics of tourism and its role in the sustainable development, 09-10 March 2010, Mohamed Khaydar University of Biskra, Algeria.

16. Yassin, Saad Ghalib and Al-Taie, Hamid Abd Al-Nabi (2004). Evaluating the websites of the first-class hotels via the internet (the case study of Jordan), Journal of the administrative Sciences' studies, Volume 31, Issue 2.

17. Adams Bruce (2004). Hotel of Companies Pushing Details Brand Sites Leads to Meteoric Growth in Booking, Hotel \& Motel management, Vol.219, no.17.

18. Beer Michael (2003). Post why total quality management programs do not persist the role of quality management and implication for Leading and TQM transformation, Decision sciences 34 (4). 
19. Daft Richard, L. (2001). Organization Theories and Design, $9^{\text {th }}$ ed., South-Western College Publishing, USA.

20. David Kroenke (2011). Using MIS, Prentice Hall.

21. Harmsworth, GR. (2006). M à ori values for land-use planning. Broadsheet, newsletter of the New Zealand Association of Resource Management, February. 37 pp - 52.

22. Jiang James (2002). Measuring information system service quality: servqual from the other side, MIS quarterly 25 (2): pp.145-166.

23. Kotler, P. \& Asmstrong, Gary (2007). Principles of marketing, prentice-Hall.

24. Laudon \& Jane kenneth Laudon (2010). On Management Information systems, $11^{\text {th }}$ ed, Prentice Hall the Int. Inc.

25. Laudon, Kenneth, C., Laudon \&, Jane, P. (2003). Essentials Information on Management of the Systems: Managing the Digital Firm, $5^{\text {th }}$ ed., Prentice-Hall Inc., New Jersey.

26. Shankar, Venkatesh \& Smith, Amy K. (2002). Customer Satisfaction and Loyalty in Online Offline Environments, Arvind Rangaswamy, e Business Research Center.

27. Zeithaml, Valeria \& Mary, Jo Bitner \& Gremler Dwagned Gremler (2006). Marketing services integrating customer focus across the firm, $4{ }^{\text {th }}$ edition, MCPP. 